\title{
Structural design of Cartesian vacuum system for loose fruit collector (LFC) machine
}

\begin{abstract}
In Sime Darby Plantation, the loose fruit collector machine has already been built, but the machine needs to be improvised as driver of the machine need to manually suck the loose fruit by getting down the tractors and open then closed the chamber when releasing the loose fruit to separator section. This cause time consuming and affect the health of the workers after non-stop bent down to collect the loose fruit. The introduction of Cartesian Vacuum System for Loose Fruit Collector (LFC) machine was based from a mechanical structure of 3D printers. This system able to grip the loose fruit suction hose and able to move in $\mathrm{x}$ and $\mathrm{y}$ axis configuration. This movement was done by use of two stepper motors by using Arduino Computer Numerical Control (CNC) Shield that operated by Grbl Controller software. It gives user nice interface to get command down manually or autonomously. Parameters that were observed included time-motion for the machine, loose fruit collected in predetermined area and capability of the suction hose. However, the test was only able to collect loose fruit that have length 26 to 31 millimeters around 58 to 62 seconds only for 0.1272 -meter square area. It is anticipated that the productivity of the current Cartesian Vacuum System for LFC can be improves by increase the suction power and increase the diameter of the hose so that it able to collect loose fruit more at a time and reduce time-consuming. Hence, this will decrease the labor work load for loose fruit collecting and increase production rate that contribute to higher national oil extraction rate (OER).
\end{abstract}

Keyword: Loose fruit; Collect; Cartesian vacuum system; Arduino CNC 